\title{
Hypertension and its Determinants Among School Going Adolescents: A Cross Sectional Study in Nepal
}

\author{
Sujata Shakya ${ }^{1}$ and Shanti Bajracharya ${ }^{2}$ \\ ${ }^{1}$ Central Department of Public Health, Institute of Medicine, Maharajgunj, Kathmandu, Nepal \\ ${ }^{2}$ College of Nursing, Nepalese Army Institute of Health Sciences, Saano Bharyang, Kathmandu, \\ Nepal
}

\author{
Correspondence: \\ Sujata Shakya \\ Central Department of Public Health \\ Institute of Medicine, \\ Maharajgunj, Kathmandu, \\ Nepal \\ Email: sujata_8@iom.edu.np
}

DOI: $10.3126 /$ jnps.v39i2.25377

Submitted on: 2019-08-26

Accepted on: 2020-03-27

Acknowledgements: We would like to heartily acknowledge Centre for Research, Tribhuvan University for providing us mini research grant for the study. We are grateful to the selected schools who provided us permission to carry out the study. Lastly, we are thankful to all the student participants who kindly agreed to participate in the study.

Funding: Mini research grant awarded by Centre for Research, Tribhuvan University, Kirtipur, Nepal

Conflict of Interest: None declared

Permission form IRB: Yes

To cite this article: Shakya $S$, Bajracharya S. Hypertension and its determinants among school going adolescents: a cross sectional study in Nepal. J Nepal Paediatr Soc. 2019;39(2): 87-94.

\section{ABSTRACT}

Introduction: Hypertension is a chronic life threatening noncommunicable disease. It increases the risk for cardiovascular diseases even leading to premature death. Almost half of the adults with hypertension had elevated blood pressure during childhood. With globalisation and lifestyle changes, adolescents are exposed to various risk factors. However, diagnosis in this population is difficult due to absence of symptoms. Thus, regular blood pressure screening is essential in these groups. This study aimed to find out the prevalence of hypertension and its determinants among the school going adolescents of Kathmandu, Nepal.

Methods: This was a descriptive cross sectional study which included five private secondary schools of Kathmandu, Nepal. The adolescent students studying in classes VIII, IX and X were the study subjects. Two stage cluster random sampling technique was used to select 356 participants. Data collection was done by doing anthropometric measurements, blood pressure measurement and through self administered questionnaire.

Results: The study depicted that the prevalence of elevated blood pressure was $12.4 \%$, stage 1 hypertension $32.3 \%$ and stage 2 hypertension $9.8 \%$. Similarly, $13.8 \%$ were overweight and $1.4 \%$ were obese. Bivariate analysis depicted significant association of prevalence of hypertension with gender, religion and obesity $(\mathrm{p}<$ 0.05 ). The multivariate analysis shows that the significant predictors of elevated blood pressure and/or hypertension were gender and obesity. Males were six times more likely to have elevated blood pressure ( $\mathrm{AOR}=6.058, \mathrm{CI}=2.571-14.274)$ and 2.8 times more likely to be hypertensive $(\mathrm{AOR}=2.838, \mathrm{CI}=1.688$ - 4.773) compared to females. Similarly, compared to obese/ overweight students, thin and normally built ones have less likelihood of having elevated blood pressure and hypertension.

Conclusions: Hypertension has been prevalent among adolescents, due to various behavioural risk factors. This is really challenging and of public health significance. Regular screening of adolescents is essential for early detection and management of hypertension.

Key Words: adolescents; determinants; hypertension; risk factors 


\section{INTRODUCTION}

The 2017 American Academy of Paediatrics (AAP) Guidelines for Childhood Hypertension (HTN) has revised HTN into three categories, that are, elevated blood pressure (BP), Stage 1 and 2 HTN. ${ }^{1}$ HTN is one of the most common life threatening non-communicable diseases. With the rise in urbanization, there is increase in sedentary lifestyles, tobacco smoking, lack of physical activity, unhealthy diet intake, harmful use of alcohol etc., which are the risk factors of HTN. ${ }^{2}$ Globally, it affects about one billion adults and is associated with more than nine million deaths annually. ${ }^{3}$ It increases the risk for cardiovascular diseases including stroke, coronary artery disease, heart failure and peripheral vascular disease. ${ }^{4}$

Childhood HTN is an established predictor of adult HTN, and it is underestimated problem in developing countries. An increasing number of healthy children and adolescents across the world are being diagnosed with HTN. ${ }^{5}$ The recent data on United States (US) children shows that prevalence of pre-hypertension was estimated to be $14 \%$ and $6 \%$ in boys and girls respectively and the prevalence of HTN was estimated to be $3-4 \%$ in many studies.$^{6-8} \mathrm{HTN}$ in children and adolescents is becoming a major concern, not only because of its rising prevalence, but also because of evidence suggesting that HTN tracks from childhood to adulthood. Almost half of adults with HTN had elevated blood pressure values during childhood. ${ }^{9}$ Similarly, adolescents are also exposed to various risk factors, mainly intake of junk food, processed food, reduced physical activity, alcohol and tobacco consumption etc. ${ }^{10}$ Not only these factors, barring treatment, control, low awareness of HTN are also seen to be one of the main causes for having these kind of diseases. Accurate identification of HTN at the earliest possible age would, therefore, reduce the chance of developing end-organ damage and its attendant morbidity and mortality. Regular screening of the adolescents is required in order to prevent the emergence of complications later in life. ${ }^{11}$

There are numerous studies conducted among the adult population, but few studies are found among the adolescents. Thus, the aim of the study was to assess the prevalence and determinants of HTN among the school going adolescents in Kathmandu, Nepal.

\section{METHODS}

This was a school based cross sectional study conducted among the students of grades VIII, IX and $\mathrm{X}$ of different private schools of Kathmandu, Nepal. Two stage cluster random sampling technique was applied for selection of the samples. Firstly, the list of all private secondary schools located in Kathmandu and the total number of students in each school was obtained from District Education Office, Kathmandu. Then random selection of five schools was done through lottery method. From each selected school (cluster), one section each from grades VIII, IX and $\mathrm{X}$ was randomly selected. All the students of the selected sections were taken as the samples. Sample size was calculated based on prevalence of $12 \%,{ }^{12}$ level of significance 0.05 , allowable error $5 \%$, design effect two and non-response rate $10 \%$. Thus, the total calculated sample size came to be 356 . The students who were absent during the data collection period were excluded from the study.

Information on demographic characteristics and risk behaviours were collected through self administered semi-structured questionnaire, which was prepared based on Global School-based Student Health Survey (GSHS), ${ }^{13}$ rigorous literature review and consultation with experts. Ethical clearance for the study was obtained from Institutional Review Board (IRB) of Tribhuwan University, Institute of Medicine. Written informed consent was taken from the parents/guardians and the study participants. All the procedures followed were in accordance with the ethical standards of Helsinki Declaration. Systolic and diastolic BP was measured by trained persons using automated digital sphygmomanometer after five minutes rest, with arm at the level of the chest. Three measurements were done at five minutes interval and the average reading was recorded. Height was measured using scale to the nearest $0.1 \mathrm{~cm}$ and weight was measured with the students on bare foot and school uniform using bathroom weighing scale to the nearest $0.1 \mathrm{~kg}$. BP, height and weight were measured following standard protocols of Centres 
for Disease Control and Prevention (CDC) 2000. ${ }^{14}$ Basal Metabolic Index (BMI) was calculated from measured weight and height. The nutritional status were categorised based on World Health Organisation (WHO) score. ${ }^{15}$

Frequencies, percentage, mean and standard deviation were calculated from the data. Chi-square test and Fisher's exact test were performed to measure the association of different variables with prevalence of HTN. Multiple logistic regression model was used for multivariate analysis in order to identify the predictors.

\section{RESULTS}

Among the selected students, six parents did not give consent and 13 students were absent during data collection, thus, in total, 19 students, were

Table 1. Socio-demographic characteristics of the respondents

\begin{tabular}{|crr|}
$\begin{array}{l}\text { Socio-demographic } \\
\text { characteristics }\end{array}$ & $\begin{array}{l}\text { Number } \\
\text { (n=356) }\end{array}$ & Percent \\
\hline Age (in years) & 145 & 40.7 \\
$12-14$ & 211 & 59.3 \\
Sex & & \\
\hline Male & 191 & 53.7 \\
Female & 165 & 46.3 \\
Religion & & \\
Hindu & 313 & 87.9 \\
Buddhist & 26 & 7.3 \\
Muslim & 7 & 2.0 \\
Christian & 7 & 2.0 \\
Others & 3 & 0.9 \\
Ethnicity & & \\
Brahmin/Chhetri & 193 & 54.2 \\
Janajati & 125 & 35.1 \\
Dalit & 6 & 1.7 \\
Madhesi & 22 & 6.2 \\
Others & 10 & 2.8 \\
Type of family & & 73.0 \\
Nuclear & 260 & 26.9 \\
Joint & 96 &
\end{tabular}

missed. Finally 356 students participated in the study.

Based on the study findings, the average age of the participants was $14.76 \pm 1.09$ years and about half were males. Most of them were Brahmin/Chhetri $(54.2 \%)$ and belonged to nuclear family (73\%) (Table 1). The prevalence of elevated BP was $12.4 \%$, stage 1 HTN $32.3 \%$ and stage 2 HTN 9.8\% (Figure 1). Similarly, $13.8 \%$ were overweight and $1.4 \%$ obese (Figure 2 ).

Gender and religion were found to be significantly associated with HTN. The prevalence of HTN significantly increases among males and Hindus ( $p$ $<0.05$ ) (Table 2). However, HTN was not significantly associated with smoking and drinking habit and physical activity. The percent of elevated BP and hypertension is significantly increased among overweight/obese compared to normal and thin participants $(\mathrm{p}<0.05)$ (Table 3$)$.

Table 4 shows the multivariate analysis of hypertension with different independent variables that were significant at $90 \%$ CI $(p<0.1)$ in bivariate analysis. Males are found to be six times more likely to have elevated blood pressure (AOR $=6.505, \mathrm{CI}=2.823-14.989)$ and 2.7 times more likely to be hypertensive $(\mathrm{AOR}=2.778, \mathrm{CI}=1.675$ - 4.609) compared to females. Similarly, compared to obese/overweight respondents, thin and normally built ones have less likelihood of having elevated blood pressure and hypertension.

\section{DISCUSSION}

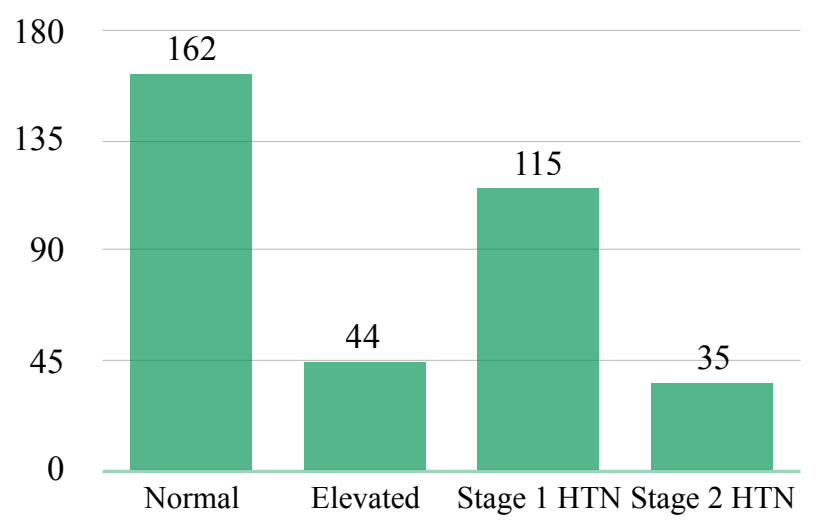

Figure 1. Prevalence of Hypertension 


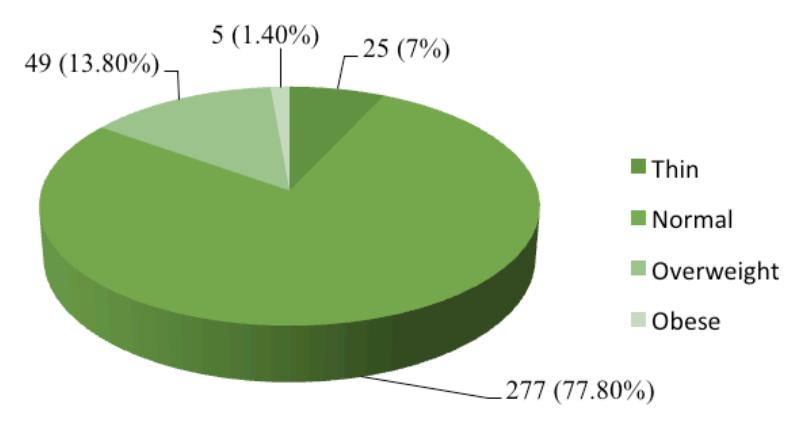

Figure 2. Prevalence of Obesity

Hypertension has been one of the burning problems identified in the society having significant implications on adolescent health in coming days. So, its early identification and intervention helps in reducing mortality and morbidity among adolescents and young adults. This study included 356 students of age 12 to 17 years from different private schools of Kathmandu, among which 191 (53.7\%) were males and 165 (46.3\%) were females studying in Grade VIII, IX and X. The students mainly belonged to Hindu (87.9\%) by religion, Brahmin/Chhetri (54.2\%) by ethnicity and nuclear family $(73 \%)$.

The mean systolic and diastolic BP was $119.13 \pm$ 12.98 and $76.02 \pm 8.98 \mathrm{~mm}$ of $\mathrm{Hg}$ respectively. The prevalence of elevated BP was $12.4 \%$, Stage 1 HTN $32.3 \%$ and Stage 2 HTN were $9.8 \%$, whereas, in the study conducted by Bell et al, the percentage of elevated BP was $19.6 \%$ and Stage 1 and Stage 2 HTN were $8.9 \%$ and $2.7 \%$ respectively. ${ }^{16}$ Similarly, the study conducted by Ujunwa FA et al. showed that $17.3 \%$ had prehypertension, $67.8 \%$ Stage 1 and $32.2 \%$ Stage 2 hypertension. ${ }^{17}$ However, as the present study referred to updated definition according to 2017 AAP guidelines for childhood HTN, ${ }^{1}$ unlike major other studies which have cited 2014 definition, ${ }^{18}$ it was difficult to compare directly with those studies.

Looking at the obesity, those with normal weight were $77.8 \%$, followed by overweight $(13.8 \%)$, obese being least in number, that was $1.4 \%$. The mean BMI calculated was $19.88 \pm 3.03 \mathrm{~kg} / \mathrm{m}^{2}$. While consistent result was seen in a study conducted in Nepal by Piryani et al., prevalence of
Table 2. Association of Hypertension with SocioDemographic Variables

\begin{tabular}{|c|c|c|c|c|}
\hline \multicolumn{2}{|c|}{ Variables } & Elevated & $\begin{array}{l}\text { Hyper- } \\
\text { tensive }\end{array}$ & $\begin{array}{c}\mathbf{p} \\
\text { value }\end{array}$ \\
\hline \multicolumn{5}{|c|}{ Age (in years) } \\
\hline $12-14$ & $\begin{array}{l}68 \\
(46.9 \%)\end{array}$ & $\begin{array}{l}19 \\
(13.1 \%)\end{array}$ & $\begin{array}{l}58 \\
40.0 \%)\end{array}$ & 0.787 \\
\hline $15-17$ & $\begin{array}{l}94 \\
(44.5 \%)\end{array}$ & $\begin{array}{l}25 \\
(11.8 \%)\end{array}$ & $\begin{array}{l}92 \\
(43.6 \%)\end{array}$ & \\
\hline \multicolumn{5}{|l|}{ Gender } \\
\hline Male & $\begin{array}{l}62 \\
(32.5 \%)\end{array}$ & $\begin{array}{l}35 \\
(18.3 \%)\end{array}$ & $\begin{array}{l}94 \\
(49.2 \%)\end{array}$ & $<0.001 *$ \\
\hline Female & $\begin{array}{l}100 \\
(60.6 \%)\end{array}$ & $9(5.5 \%)$ & $\begin{array}{l}56 \\
(33.9 \%)\end{array}$ & \\
\hline \multicolumn{5}{|l|}{ Religion } \\
\hline Hindu & $\begin{array}{l}142 \\
(45.4 \%)\end{array}$ & $\begin{array}{l}36 \\
(11.5 \%)\end{array}$ & $\begin{array}{l}135 \\
(43.1 \%)\end{array}$ & $0.008 *$ \\
\hline Buddhist & $\begin{array}{l}16 \\
(61.5 \%)\end{array}$ & $1(3.8 \%)$ & $9(34.6 \%)$ & \\
\hline Others & $\begin{array}{l}4 \\
(23.5 \%)\end{array}$ & $\begin{array}{l}7 \\
(41.2 \%)\end{array}$ & $6(35.3 \%)$ & \\
\hline
\end{tabular}

*p value significant at 0.05

overweight was $12.2 \%$ (95\% CI 8.9 to 15.5$)$ and the mean BMI was $20.5 \mathrm{~kg} / \mathrm{m}^{2}{ }^{19}$ This may be because the cultural pattern and the exposure to the environment seems to be similar.

It was found that BP increases with age in the study conducted in Enugu, South East Nigeria. ${ }^{17}$ However, the association was not statistically significant in the present study. Among hypertensives, $49.2 \%$ were boys and $33.9 \%$ were girls where the percent of males was found significantly high. The findings were similar to the study conducted by Mousa et al., ${ }^{20}$ while contrast with the study conducted by Bala $\mathrm{S}$ et al. ${ }^{12}$ and Ujunwa FA et al. ${ }^{17}$ Similarly, in this study, Hindu had significantly high prevalence of HTN compared to and other religion $(p<0.05)$. This finding might be due to higher percentage of Hindus compared to Buddhists and other religions in the study sample. 
Table 3. Association of Hypertension with Lifestyle Factors

\begin{tabular}{|c|c|c|c|c|}
\hline Variables & Normal & Elevated & Hypertensive & p value \\
\hline \multicolumn{5}{|l|}{ Smoking past 30 days } \\
\hline Yes & $7(33.3 \%)$ & $3(14.3 \%)$ & $11(52.4 \%)$ & \multirow[t]{2}{*}{0.436} \\
\hline No & $155(46.3 \%)$ & $41(12.2 \%)$ & $139(41.5 \%)$ & \\
\hline \multicolumn{5}{|l|}{ Drink alcohol past 30 days } \\
\hline Yes & $24(49.0 \%)$ & $4(8.2 \%)$ & $21(42.9 \%)$ & \multirow[t]{2}{*}{0.664} \\
\hline Normal & $138(45.0 \%)$ & $40(13.0 \%)$ & $129(42.0 \%)$ & \\
\hline \multicolumn{5}{|l|}{ Physical activity done } \\
\hline$<4$ days/week & $88(44.2 \%)$ & $23(11.6 \%)$ & $88(44.2 \%)$ & \multirow[t]{2}{*}{0.649} \\
\hline$\geq 4$ days/week & $74(47.1 \%)$ & $21(13.4 \%)$ & $62(39.5 \%)$ & \\
\hline \multicolumn{5}{|l|}{ Walking/riding bicycle } \\
\hline$<4$ days/week & $61(48.0 \%)$ & $17(13.4 \%)$ & $49(38.6 \%)$ & \multirow[t]{2}{*}{0.596} \\
\hline$\geq 4$ days/week & $101(44.1 \%)$ & $27(11.8 \%)$ & $101(44.1 \%)$ & \\
\hline \multicolumn{5}{|l|}{ Intake of soft drinks } \\
\hline$<1$ time/day & $119(45.6 \%)$ & $34(13.0 \%)$ & $108(41.4 \%)$ & \multirow[t]{2}{*}{0.784} \\
\hline$\geq 1$ time/day & $43(45.3 \%)$ & $10(10.5 \%)$ & $42(44.2 \%)$ & \\
\hline \multicolumn{5}{|c|}{ Frequency of eating from restaurant } \\
\hline$<4$ days/week & $112(44.6 \%)$ & $34(13.5 \%)$ & $105(41.8 \%)$ & \multirow[t]{2}{*}{0.567} \\
\hline$\geq 4$ days/week & $50(47.6 \%)$ & $10(9.5 \%)$ & $45(42.9 \%)$ & \\
\hline \multicolumn{5}{|l|}{ Junk food consumption } \\
\hline$<4$ days/week & $63(39.9 \%)$ & $26(16.5 \%)$ & $69(43.7 \%)$ & \multirow[t]{2}{*}{0.05} \\
\hline$\geq 4$ days/week & $99(50.0 \%)$ & $18(9.1 \%)$ & $81(40.9 \%)$ & \\
\hline \multicolumn{5}{|l|}{ Frequency of meat intake } \\
\hline$<4$ days/week & $135(45.0 \%)$ & $39(13.0 \%)$ & $126(42.0 \%)$ & \multirow[t]{2}{*}{0.719} \\
\hline$\geq 4$ days/week & $19(50.0 \%)$ & $3(7.9 \%)$ & $16(42.1 \%)$ & \\
\hline \multicolumn{5}{|l|}{ Extra salt intake } \\
\hline Yes & $9(33.3 \%)$ & $1(3.7 \%)$ & $17(63.0 \%)$ & \multirow[t]{2}{*}{0.071} \\
\hline No & $153(46.5 \%)$ & $43(13.1 \%)$ & $133(40.4 \%)$ & \\
\hline \multicolumn{5}{|l|}{ BMI } \\
\hline Thin & $17(68.0 \%)$ & $2(8.0 \%)$ & $6(24.0 \%)$ & \multirow[t]{3}{*}{$<0.001^{*}$} \\
\hline Normal & $135(48.7 \%)$ & $33(11.9 \%)$ & $109(39.4 \%)$ & \\
\hline Overweight/obese & $10(18.5 \%)$ & $9(16.7 \%)$ & $35(64.8 \%)$ & \\
\hline
\end{tabular}

*p value significant at 0.001

Obesity and overweight are one of the risk factors of HTN. In obese children, activation of the sympathetic nervous system shifts the arterial pressure control mechanism of diuresis and natriuresis to higher BP levels. This might be the possible reason illuminating the association. ${ }^{21}$ In this study, BMI was significantly associated with HTN where $64.8 \%$ with obesity/overweight had
HTN $(\mathrm{p}<0.05)$. This finding is similar to other studies. ${ }^{17,22,23}$ However, no statistically significant association was seen in study by Bala $\mathrm{S}$ et al. ${ }^{12}$ Similarly, there was no correlation between high BP and overweight in a study done by Chirag BA et al. ${ }^{22}$ After controlling all other variables, gender and BMI were found to be the strong predictors of elevated BP and HTN. Males are six times more 
Table 4. Multivariate analysis for association of hypertension with different variables

\begin{tabular}{|c|c|c|c|c|c|}
\hline $\begin{array}{l}\text { Category of } \\
\text { hypertension }\end{array}$ & Study variables & Crude OR & Adjusted OR & $95 \%$ CI & p value \\
\hline \multirow[t]{7}{*}{ Elevated } & Sex & & & & \\
\hline & Male & 6.272 & 6.505 & $2.823-14.989$ & $<0.001^{*}$ \\
\hline & Female & Ref & & & \\
\hline & Obesity & & & & \\
\hline & Thin & 0.131 & 0.107 & $0.017-0.669$ & 0.017 \\
\hline & Normal & 0.272 & 0.246 & $0.087-0.701$ & $0.009 *$ \\
\hline & Overweight/Obese & Ref & & & \\
\hline \multirow[t]{10}{*}{ Hypertensive } & Sex & & & & \\
\hline & Male & 2.707 & 2.778 & $1.675-4.609$ & $<0.001^{*}$ \\
\hline & Female & Ref & & & \\
\hline & Religion & & & & \\
\hline & Hindu & 0.634 & 1.516 & $0.688-3.341$ & 0.302 \\
\hline & Buddhist and others & Ref & & & \\
\hline & Obesity & & & & \\
\hline & Thin & 0.101 & 0.064 & $0.018-0.224$ & $<0.001 *$ \\
\hline & Normal & 0.231 & 0.217 & $0.098-0.478$ & $<0.001 *$ \\
\hline & Overweight/Obese & Ref & & & \\
\hline
\end{tabular}

${ }^{*} p$ value significant at 0.001

likely to have elevated $\mathrm{BP}(\mathrm{AOR}=6.058, \mathrm{CI}=$ $2.571-14.274)$ and 2.8 times more likely to have HTN $(\mathrm{AOR}=2.838, \mathrm{CI}=1.688-4.773)$ compared to females. This might be due to increased BMI among males and increased tendency to eat fast food. A study done in two cities of Egypt showed that $\operatorname{sex}(\mathrm{OR}=0.551, \mathrm{CI}=0.417-0.729)$ had increased estimated risk of HTN and females had lesser odds of having risk of HTN. ${ }^{20}$

Similarly, in the present study, compared to obese/ overweight respondents, thin and normally built ones have less likelihood of having elevated BP and HTN. This shows that with increasing obesity/ overweight, there is increased chance of having elevated BP and HTN. The findings were consistent with the study by Mousa et al., in which BMI (OR $=1.468, \mathrm{CI}=1.256-1.715)$ is one of the best predictors of HTN. ${ }^{20}$ Similarly, another study done in North Indian City found that obesity significantly increased the odds of both HTN as well as pre hypertension. ${ }^{24}$
This is a multi-institutional study with a representative sample. Thus, the findings might be generalised in other similar settings. However, as the study was conducted in the capital of the country, this might not represent the entire population. Another limitation of the study might be, being a cross-sectional study, no causal relationship could be established. The information on behaviours/lifestyles like smoking and alcohol use, physical activity, dietary habit etc was entirely based on self reporting. This might pose question on reliability of the information. Similarly, assessment of food habits was based on the respondents' memory which may be subject to recall bias.

\section{CONCLUSIONS}

Our study revealed that the prevalence of elevated BP was $12.4 \%$, Stage 1 HTN $32.3 \%$ and Stage 2 HTN 9.8\%. The significant predictors of HTN were found to be gender and obesity. Obesity and overweight among children and adolescents has been prevalent in the urban areas these days as 
adolescents substitute their lunch and dinner by junk foods and drinks, omitting breakfast, sedentary lifestyle etc, which directly leads to increase in hypertension. As the roots of essential HTN extend into adulthood, routine screening of BP should be emphasised during adolescence. Students spend most of their time in school environment. So, school has to focus on promoting positive health behaviour. Strategies should be adopted for addressing the healthy foods in the school premises as well as outside through behavioural skill training and making sports as a part of compulsory physical education activities. This study helps to identify the prevalence and associated determinants of HTN during adolescence which are amendable for prevention of complications in adulthood. This can lead to reduction in mortality and morbidity of the population as a whole.

\section{REFERENCES}

1. Flynn JT. 2017 AAP Guidelines for Childhood Hypertension. Paediatric Care Online 2017. Available from: https:// solutions.aap.org/DocumentLibrary/pcowebinars/2017\%20Hypertension\%20Webinar.pdf.

2. Singh PS, Singh PK, Zafar KS, Sharma H, Yadav SK, Gautam RK, et al. Prevalence of hypertension in rural population of Central India. 2017;5(4):1451-5. DOI: http://dx.doi.org/10.18203/2320-6012.ijrms20171244

3. Chobanian AV, Bakris GL, Black HR, Cushman WC, Green LA, Izzo JL, et al. The seventh report of the joint national committee on prevention, detection, evaluation, and treatment of high blood pressure: the JNC 7 Report. JAMA. 2003;289:2560-72. DOI: 10.1001/jama.289.19.2560

4. Goldstein IB, Shapiro D, Weiss RE. How family history and risk factors for hypertension relate to ambulatory blood pressure in healthy adults. J Hypertens. 2008;26:276-83. DOI: 10.1097/hjh.0b013e3282f15c27.

5. WHO. Major cause of death November 2012 [Internet]. 2012 [cited 2017 Jan 17]. Available from: www.who.int/

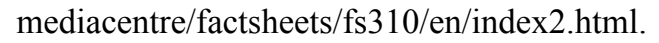

6. WHO. Non-communicable disease in South East Asia region. Situation and response. New Delhi: South East Asia regional office, [Internet]. 2011 . Available from: www. searo.who.int/.../ 2011_non_communicable_diseases_in_the_south_east_asia_re.

7. Ostachega Y, Carmell M. Trends of elevated blood pressure among children and adolscents data from the National Health and Nutrition survey. 1988-2006. Am J Hypertens 2009;22:59-67. DOI: 10.1038/ajh.2008.312

8. Kaplan NM, Victor CG. Clinical hypertension. 10th ed. Philadelphia,PA: Lippincot Williams and Wilkins; 2010.

9. US dept of Health and Human services. Office of Disease Prevention and Health Promotion. Healthy people 2020. Topics and objectives, Heart disease and stroke, [Internet]. 2020. Available from :www.healthypeople.gov/2020/ topics-objectives/topic/heart-disease-and-stroke.

10. Strategy handbook. Rashtriyakishorswasthyakaryakram [Internet]. Adolescent health division ministry of health and family welfare. Government of India; 2017. Available from: www.dropbox.com/ s/0oj4p422y7st4ku/RKSK \%20Strategy\%20Handbook.pdf.

11. Beckett LA, Rosner B, Roche AF. Serial changes in blood pressure from adolescence into adulthood. Am J Epidemiol. 1992;135. DOI: 10.1093/oxfordjournals.aje.a116217.

12. Bala S, Sandeep M, Prasad GKN, Chandrasekhar A. Prevalence and determinants of pre-hypertension and hypertension among urban high school students of Hyderabad. Nat J Res Commu Med. 2017 Dec;6(4):295-9. DOI: 10.26727/NJRCM.2017.6.4.295-99.

13. Centres for Disease Control and Prevention (CDC). Global School-based Student Health Survey (GSHS). 2013 Core Questionnaire Modules. [Internet]. 2013 [cited 2017 Jan 13]. Available from: https://www.who.int/ncds/ surveillance/gshs/GSHS_Core_Modules_2013_English.pdf.

14. Kuczmarski RJ, Ogden CL, Guo SS. 2000 CDC growth charts for the United States: Methods and development. National Center for Health Statistics. Vital Health Stat. 2002;246:1-190. PMID: 12043359 
15. WHO. WHO AnthroPlus for personal computers Manual: Software for assessing growth of the world's children and adolescents [Internet]. Geneva; 2009. Available from: http://www.who.int/growthref/tools/en/.

16. Bell CS, Samuel JP, Samuels JA. Prevalence of Hypertension in Children, Applying the New American Academy of Pediatrics Clinical Practice Guideline. Hypertension 2019;73:148-152. DOI:10.1161/hypertensionaha.118.11673.

17. Ujunwa FA, Ikefuna AN, Nwokocha ARC, Chinawa JM. Hypertension and Prehypertension among Adolescents in Secondary Schools in Enugu, South East Nigeria. Italian J Paediatrics 2013 Nov;39(1):70. DOI: 10.1186/1824-7288-39-70.

18. National High Blood Pressure Education Programme Working Group on High Blood Pressure in Children and Adolescents. The fourth report on the diagnosis, evaluation and treatment of high blood pressure in children and adolescents. Paediatrics 2004;114:555-76.

19. Piryani S, Baral KP, Pradhan B, Poudyal AK, Piryani RM. Overweight and its associated risk factors among urban school adolescents in Nepal: a cross-sectional study. BMJ Open 2016;6:e010335. DOI:10.1136/bmjopen-2015010335 .

20. Moussa M, Moussa M, El-mowafy RI, El-Ezaby HH. Prevalence of hypertension and associated risk factors among university students: Comparative study. JNEP 2016 Jan;6(5):19-27. Doi 10.5430/jnep.v6n5p19.

21. Kotsis V, Stabouli S, Papakatsika S, Rizos Z, Parati G. Mechanisms of obesity-induced hypertension. Hypertens Res 2010;33:386-93. DOI: 10.1038/hr.2010.9.

22. Chirag BA, Chavda J, Kakkad KM, Damor P. A Study of Prevalence of Hypertension in School Children. Guj Med J 2013 Dec;68(2):79-81.

23. Mahanta TG, Mahanta B, Deuri A, Baruah S, Rasailey R, Mahata B. Determinants of Hypertension among School Going Adolescents Aged 13-15 yrs in Asaam. Clin Epidemiol Glob Health. 2017. DOI:10.1016/j.cegh.2017.08.005.

24. Prasad S, Masood J, Srivastava AK, Mishra P. Elevated Blood Pressure and Its Associated Risk Factors among Adolescents of a North Indian City - A Cross-sectional Study. Indian J Community Med. 2017 Jul-Sep;42(3):155158. DOI: $10.4103 / \mathrm{ijcm} . I J C M \_106 \_16$. 